University of California, Hastings College of the Law UC Hastings Scholarship Repository

Faculty Scholarship

2017

\title{
The Moral-Hazard Effect of Liquidated Damages: An Experiment on Contract Remedies
}

Ben Depoorter

UC Hastings College of the Law, depoorter@uchastings.edu

Sven Hoeppner

Lars Freund

Follow this and additional works at: https://repository.uchastings.edu/faculty_scholarship

\section{Recommended Citation}

Ben Depoorter, Sven Hoeppner, and Lars Freund, The Moral-Hazard Effect of Liquidated Damages: An Experiment on Contract Remedies, 173 J. Institutional \& Theoretical Econ. 1 (2017).

Available at: https://repository.uchastings.edu/faculty_scholarship/1593 


\title{
The Moral-Hazard Effect of Liquidated Damages: An Experiment on Contract Remedies
}

\author{
by
}

\author{
Sven Hoeppner, Lars Freund, and Ben Depoorter*
}

\begin{abstract}
Recent evidence suggests that liquidated-damages clauses provide efficiency advantages by crowding out contracting parties' deontological concerns about efficient breach. In this paper we highlight an important downside to damage stipulations by parties. Based on findings obtained in a controlled laboratory experiment, we suggest that express damage stipulations trigger negative reciprocity and moral hazard, reducing performance by contract promisors. Such negative effects are absent when damages are exogenously imposed. Moreover, our results indicate that when stipulating damages, contract parties attain less cooperative surplus than when they are subject to an exogenously imposed remedy. Principals, not agents, bear this loss. (JEL: J, E, L, K12, D63, D86, L14, C25, C70, C91)
\end{abstract}

\section{Introduction}

The economic literature on contract law has identified various benefits of partystipulated remedies. Early contributions recognize liquidated damages as enabling contracting parties to signal the actual value of their goods and services and provide efficient insurance for their preferences (Goetz and Scott, 1977; Kronman and Posner, 1979; Schwartz, 1990; Talley, 1994). ${ }^{1}$ Party-stipulated awards are heralded also as an instrument that can be used by contracting parties to induce efficient

* Sven Hoeppner (corresponding author): research fellow at the Center for Advanced Studies in Law and Economics (CASLE), Ghent University, Belgium, and affiliate researcher at the Department for Business, Economics, and Social Sciences, University of Cologne, Germany; Lars Freund: research fellow at the Max Planck Institute for Research on Collective Goods, Bonn, Germany; Ben Depoorter: Professor of Sunderland Chair at Hastings College of Law, University of California, San Francisco (CA), U.S.A., director of CASLE, Ghent University, Belgium, and affiliate scholar at the Center for Internet \& Society, Stanford Law School, Berkeley (CA), U.S.A. We are grateful for helpful discussions and critical comments by Christoph Engel, Andreas Engert, Paul Heald, André Schmelzer, Alexander Stremitzer, and Theresa Wenning. We are also indebted to the audience of the 2016 JITE Conference on "The Remedies Game" held in Sibiu, Romania. André Schmelzer and Theresa Wenning deserve special thanks for enthusiastically providing research support. Financial support of the Deutsche Forschungsgemeinschaft (DFG) is gratefully acknowledged.

1 For experimental findings, see Sloof et al. (2003). 
investments (Edlin, 1996; Edlin and Reichelstein, 1996; Hart and Moore, 1999; Maskin and Tirole, 1999).

A strand of scholarship focuses on the beneficial effects of contemplating and expressing damage remedies ex ante (Rea, 1984; Stole, 1992; Spier and Whinston, 1995). In particular, formalizing damage awards forces parties to deliberate carefully about the expected value of and the potential risks presented by the contract. ${ }^{2}$

Several valuable recent contributions focus on the effect of party-stipulated remedies on the interpersonal dynamics between contracting parties. Experimental evidence shows that subjects set the penalties for breach at lower amounts when asked to draft a liquidated-damages clause ex ante than when asked to determine the appropriate level of damages for breach ex post (Wilkinson-Ryan and Baron, 2009). The express stipulation of damage remedies in case of breach has also been found to change the meaning of performance and moral intuitions about breach. By contemplating compensation prior to breach, liquidated-damages stipulations avoid moral outrage of contract breach between contracting parties. This may promote efficiency because, as shown by recent empirical evidence, the presence of liquidated-damages clauses can crowd out contracting parties' concerns about efficient contract breaches (Wilkinson-Ryan, 2010).

This article identifies a hereto unexplored downside of contract for damage remedies. We argue that explicitly designating damage awards ex ante may negatively affect cooperation and performance. Specifically, we conjecture that by specifying the rights and obligations of the agent in the event of contract breach, liquidated-damages clauses trigger negative reciprocity. In this process, resentment over the principal's express stipulation of damages may induce lower overall performance by the agent than when the sanction for breach is set exogenously by courts.

We examine our intuition by deriving predictions from a formal model and testing the ensuing predictions in a controlled laboratory experiment. Following the modeling framework of Cox, Friedman, and Gjerstad (2007), we assume that agents are egocentric altruists. Employing a modified trust game, we apply a set of treatments to distinguish the effects of various contract remedies, including expectation damages (with varying levels of uncertainty about the damage award) and liquidated damages.

The main findings can be summarized as follows. First, the results confirm that, as compared to expectation damages set exogenously, agents perform at lower levels when a principal has stipulated damages. Second, our data suggests that, based on their investment decisions, principals do not appear to anticipate moral hazard as triggered by stipulating damages. Third, the role of negative reciprocity in driving moral hazard on behalf of agents is confirmed by our finding that performance is unaffected when damage remedies are imposed exogenously in the experiment.

${ }^{2}$ But see Eisenberg (1995) for a critical evaluation of the ex ante ability of parties to imagine all possible situations involving breach. 
Overall, our findings provide a cautionary note about the alleged efficiency advantages of party-designated damages. Although stipulating damages may remove moral inhibitions about breach when there are efficient breach opportunities, this benefit must be weighed against the reduced cooperation and the quality of performance due to negative reciprocity and the lack of interpersonal trust. Moreover, liquidated damages induce inefficient, excessive investments, since principals fail to anticipate the reduced performance by agents in response to stipulated damages.

This article proceeds as follows. Section 2 describes the experiment, including treatments, procedure, and participant sample. Section 3 outlines the model predictions and various hypotheses. Section 4 presents the results. In section 5 we discuss the policy implications before we conclude. Appendices and supplementary material are available online at http://www.coll.mpg.de/sites/www/files/ HFD-JITE-appendices.zip.

\section{Game Setup and Experiment}

To examine the effects of party-designated and court-imposed contract remedies, we employ a modified version of the trust game. Figure 1 depicts the base game, anticipating the experiment's parametrization. ${ }^{3}$

Figure 1

The Base Game

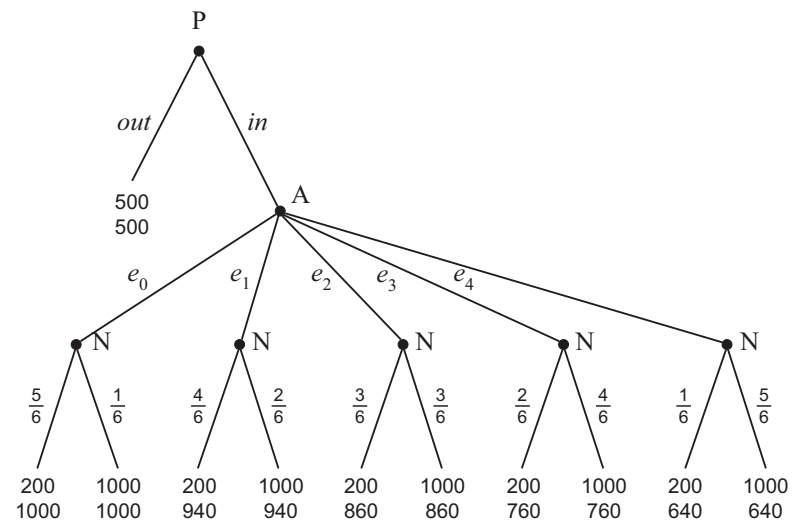

In this sequential game, the principal $(\mathrm{P})$ moves first by deciding whether to invest in a project, $a_{\mathrm{P}} \in\{$ in, out $\}$, that an agent (A) will execute. If P selects $a_{\mathrm{P}}=$ out , no contract is agreed upon and $\mathrm{P}$ and A receive outside option payoffs $O_{\mathrm{P}}$ and $O_{\mathrm{A}}$, respectively. The outside option payoffs correspond to the players' endowments at the outset of the game. If $\mathrm{P}$ selects $a_{\mathrm{P}}=i n, \mathrm{P}$ forms a contract with A to carry out a

\footnotetext{
${ }^{3}$ See Appendix B (online) for the full parametrization in all treatments.
} 
project. P pays a fixed wage $w$ to $\mathrm{A}$ and in turn receives the benefits of the project. A moves second by selecting his costly effort level $a_{\mathrm{A}} \in\left\{e_{0}, e_{1}, e_{2}, e_{3}, e_{4}\right\}$. We denote A's effort costs with $\Psi\left(a_{A}\right)$ and assume $\Psi^{\prime}(\cdot)>0, \Psi^{\prime \prime}(\cdot)>0$ (convexity). A's choice is unobservable.

Similarly to Charness and Dufwenberg (2006), the project stochastically generates payoff for P. Two states of the world, $s \in\{S, F\}$, can occur. If the project succeeds $(s=S)$, $\mathrm{P}$ receives profit $\Pi_{\mathrm{P}}^{S}$. If the project fails $(s=F)$, however, $\mathrm{P}$ obtains profit $\Pi_{\mathrm{P}}^{F}$. Note that $\Pi_{\mathrm{P}}^{S}>\Pi_{\mathrm{P}}^{F}, \Delta \Pi_{\mathrm{P}}=\Pi_{\mathrm{P}}^{S}-\Pi_{\mathrm{P}}^{F}$. The probability of success depends on how much effort A invests. With probability $\operatorname{Prob}[s=S]=q\left(a_{\mathrm{A}}\right)$ the project succeeds. The more effort A invests in the task, the higher the probability of success, i.e., $q^{\prime}\left(a_{\mathrm{A}}\right)>0$. Due to the stochastic nature of the project, $\Pi_{\mathrm{P}}$ is an imperfect signal for A's effort choice. Therefore, A's effort level is not contractible.

We use this modified trust game because it captures essential elements of a realworld contract. $\mathrm{P}$ and $\mathrm{A}$ can realize a cooperative surplus. $\mathrm{P}$ pays a wage, and A invests effort in the completion of the transaction. If they do not form a contract, each party only receives the low outside option payoff. Therefore, rational parties would want to credibly commit. Moreover, exchange is deferred in that completing the transaction involves the passage of time. The passage of time between commitment and response creates uncertainty and risk. Specifically, A's action in response the P's commitment is not contractible, because A's effort is unobservable and the outcome is only an imperfect signal for A's effort choice. Therefore, A has an incentive to behave opportunistically after concluding the contract (moral hazard). $\mathrm{P}$ may foresee this and, in turn, decide not to cooperate at all.

\subsection{Treatments}

In a baseline treatment (BASE), participants play the pure game as described. Players can earn points by playing the game. The parametrization of the game corresponds to Figure 1. BASE provides a benchmark for effort choices of players A and investment choices of players $\mathrm{P}$, absent remedies.

In a next treatment, we implement a liquidated-damages mechanism. This liquidated-damages treatment (LDT) modifies BASE by expanding the choices of player P. Before $\mathrm{P}$ makes her investment decision, she can stipulate to enforce a transfer payment of 400 points from $\mathrm{A}$ in case the low payoff occurs. Therefore, LDT contains two additional moves for P. First, prior to making her investment decision, $\mathrm{P}$ decides whether to stipulate the transfer payment. ${ }^{4}$ Second, if a low payoff occurs following A's effort decision, $\mathrm{P}$ decides whether to enforce the previously

\footnotetext{
4 Note that we assume unilateral damage stipulation. In many instances, parties of course negotiate about a liquidated-damages clause. As a liquidated-damages clause functions like an insurance for the promisee, a rational promisor may ask for an insurance premium. Consequently, the price for the promisor's services would increase. However, when there is imbalance in bargaining power, the contract can have a take-it-or-leave-it character: either the promisor accepts the contract with the liquidated-damages clause or not at all. We assume such an extreme distribution of bargaining power in order to sustain a tractable model and a clean implementation in the experiment.
} 
stipulated transfer payment. Before A decides on effort, she observes whether $\mathrm{P}$ stipulated a transfer payment. Then A makes her effort decision as in BASE, with a potentially pending decision of $\mathrm{P}$ to enforce a transfer payment. Note that the transfer payment of 400 points is an expectation damages measure. Absent remedies (BASE), the expected value of selecting $a_{\mathrm{P}}=$ in is 600 points. However, P receives 200 points even if the project fails. Therefore, the transfer of 400 points protects P's anticipated interest from the completion of the project.

In an additional treatment, we implement regular court-imposed damages. In this regular damages treatment (RDT), we also expand the choices of player P. Specifically, $\mathrm{P}$ decides whether to claim a transfer payment from player A after player A maintains her effort level and the low payoff occurs. In contrast to LDT, player $\mathrm{P}$ cannot stipulate the transfer payment in advance. Rather, the possibility of claiming a transfer payment is provided exogenously. Regarding the amount of the transfer in RDT, we incorporate a prominent aspect of damage awards: perfectly compensatory damages are difficult to assess, and thus the award can be underor overcompensatory. To capture this real-life feature of court-imposed damage awards, P's decision to claim a transfer payment triggers the lottery $(300,0.5 ; 500)$. Compared to the expectation damage measure of 400 points, a transfer payment of 300 points is undercompensatory and a transfer payment of 500 is overcompensatory. Both outcomes are equally likely.

Note that our attempt to distinguish the different effects of stipulated and regular damages faces the following identification problem: while the remedy in LDT is party-designated (endogenous) and fixed, the remedy in RDT is exogenously imposed and risky. We address this problem by using a fourth treatment that is similar to RDT except that the potential transfer is fixed at 400 points. This fixed-damages treatment (FDT) facilitates disentangling the effects between LDT and RDT.

Finally, tentative observable differences in A's behavior between BASE and all remedy treatments are confounded insofar as the transfer potentially reduces A's payoff, while enlarging P's expected payoff. The payoff reduction as such creates an economic incentive for A. However, A's effort decision may also depend on how he cares about other people. To disentangle the effects of remedies on standard and other-regarding preferences, we implement a no-transfer treatment (NTT). In NTT, A still receives her wage of 500 points. However, if the project fails and $\mathrm{P}$ receives the low payoff, A suffers a payoff reduction of 400 . The points are not transferred from A to P. This reduction is neither designated nor claimed by P. Rather, the reduction is automatically imposed by the experimenter. Therefore, anticipating the "remedy" will only affect A's standard preferences concerning his own payoff; it will not affect A's preferences regarding the payoff of P. Note that we did not make this payoff reduction contingent on any decisions by P. Such a design choice would resemble punishment of A by $\mathrm{P}$. With an automatic trigger, we avoid replacing A's other-regarding preferences by her beliefs about P's punishment behavior. This design choice comes at a potential cost, however. Differences in A's effort choices between NTT and, for instance, FDT may be caused by the transfer nature of the remedy and/or by P's decision to claim that remedy. Both are absent in NTT. How- 
ever, seeing that the decision to claim the remedy is a strictly dominant strategy for $\mathrm{P}$, we do not think that A will reasonably expect that $\mathrm{P}$ will not claim the remedy. ${ }^{5}$ Therefore, we do not expect any effect from A making his effort decision before knowing whether $\mathrm{P}$ triggers the transfer.

\subsection{Procedure}

We conducted our experiment at the Cologne Laboratory for Economic Research in May and June 2016. We used z-Tree (Fischbacher, 2007) to program the experiment. The experiment consisted of 10 sessions, and no subjects participated in more than one session. On average, a session lasted 29.60 minutes, and participants earned 9.59 EUR. The final payoff consisted of a show-up fee of 4 EUR in addition to a participant's incentive-compatible earnings from the experiment.

We randomly assigned participants to treatments. When participants arrived in the laboratory, they sat down in their separate cubicles, where they received the instructions for the first part of the experiment. We instructed participants not to communicate, randomly assigned participants to roles of player $\mathrm{P}$ and player A, and randomly paired players $\mathrm{P}$ with players $\mathrm{A}$. Upon reading the instructions, participants could raise their hand so that one of the experimenters could come over and answer any questions a participant might have.

The instructions for the first part informed participants about the choices of the players, the sequence of the choices, how choices influenced the points that could be accumulated, and how points translated into payoffs at the end of the experiment (200 points $=1$ EUR). ${ }^{6}$ Participants also learned that they were randomly paired with another participant and that all choices would remain completely anonymous. Finally, the instructions mentioned that instructions for the second part of the experiment would be announced once the first part of the experiment was completed.

When the first part commenced, each participant learned about her role and played the modified trust game in her role and treatment condition. Note that players A made conditional effort choices for each possible information set. That is, we employed the strategy method to elicit effort choices of players A outside the actual course of play (Selten, 1967; Mitzkewitz and Nagel, 1993).

Following the first part of the experiment, we elicited participants' risk attitudes (Holt and Laury, 2002), measured their ambiguity aversion (Gneezy, Imas, and List, 2015), and determined their social-value orientation (Crosetto, Weisel, and Winter, 2012). Instructions for these posttests followed on screen. All posttests were incentivized.

${ }^{5}$ In fact, in the experiment only 2 out of 157 players $P$ ever abstained from claiming the transfer when the low payoff occurred.

${ }^{6}$ See Appendix A (online) for full text instructions translated from German to English. 


\subsection{Sample}

We used ORSEE (Greiner, 2015) to invite a total of 320 participants consisting of 64 participants per treatment. We collected choice data from 314 participants. Backup invitations were not enough to compensate for no-shows in NTT (60 participants) and LDT (62 participants). The average participant was slightly older than 24 years and was on her 6th semester of studies. $53.5 \%$ of the sample was female.

\section{Model Predictions and Hypotheses}

We derive predictions contingent on the contract remedy from a formal model. Our predictions concern both A's effort decision $a_{\mathrm{A}}$ and the likelihood of P selecting $a_{\mathrm{P}}=i n$. Note that A's effort choice depends on P's decision.

To summarize our modified version of the trust game (see formal description at the beginning of section 2), we formalize P's payoffs as

$$
\Pi_{\mathrm{P}}= \begin{cases}O_{\mathrm{P}} & \text { if } a_{\mathrm{P}}=\text { out }, \\ \Pi_{\mathrm{P}}^{F} & \text { if } a_{\mathrm{P}}=\text { in } \text { and } s=F, \\ \Pi_{\mathrm{P}}^{S} & \text { if } a_{\mathrm{P}}=\text { in } \text { and } s=S,\end{cases}
$$

with $\Pi_{\mathrm{P}}^{F}<O_{\mathrm{P}}<\Pi_{\mathrm{P}}^{S}$, and A's payoffs as

$$
\Pi_{\mathrm{A}}\left(a_{\mathrm{A}}\right)= \begin{cases}O_{\mathrm{A}} & \text { if } a_{\mathrm{P}}=\text { out }, \\ O_{\mathrm{A}}+w-\Psi\left(a_{\mathrm{A}}\right) & \text { if } a_{\mathrm{P}}=i n,\end{cases}
$$

with $\Psi\left(a_{\mathrm{A}}\right)<w$, such that the participation constraint is satisfied. Moreover, we assume that cooperation would be socially beneficial, i.e.,

$$
O_{\mathrm{P}}+O_{\mathrm{A}}<q\left(a_{\mathrm{A}}\right) \Pi_{\mathrm{P}}^{S}+\left(1-q\left(a_{\mathrm{A}}\right)\right) \Pi_{\mathrm{P}}^{F}+O_{\mathrm{A}}+w-\Psi\left(a_{\mathrm{A}}\right) .
$$

Given standard preferences, our modified trust game exhibits the common dilemma character. Assume that $\mathrm{A}$ is risk-averse and generates utility from income with a twice differentiable utility function $u(\cdot)$, with $u^{\prime}(\cdot)>0, u^{\prime \prime}(\cdot) \leq 0$ (concavity). Given $a_{\mathrm{P}}=i n$, A maximizes $u\left(O_{\mathrm{A}}+w-\Psi\left(a_{\mathrm{A}}\right)\right)$. As cost increases in effort but the remaining payoff components are effort-independent, A provides the lowest effort level $e_{0}$ (moral hazard). P anticipates A's choice and plays $a_{\mathrm{P}}=o u t$ if, and only if, her expected benefit when $a_{\mathrm{P}}=e_{0}$ is less than from her outside option, i.e.,

$$
q\left(e_{0}\right) u\left(\Pi_{\mathrm{P}}^{S}\right)+\left(1-q\left(e_{0}\right)\right) u\left(\Pi_{\mathrm{P}}^{F}\right)<u\left(O_{\mathrm{P}}\right) .
$$

For the remainder of the paper and in anticipation of the experiment's parametrization, we assume that the expression (1) holds. ${ }^{7}$ The resulting unique backwardinduction solution $\left(\right.$ out,$\left.e_{0}\right)$ is inefficient.

\footnotetext{
7 An assumption to the contrary would be rather uninteresting, as $a_{\mathrm{P}}=$ in would become a strictly dominant strategy for P. The players would not face a social dilemma.
} 


\subsection{Base Game and Reciprocity Motives}

For the remainder of the paper, we do not confine ourselves to standard preferences. Economists have recently begun explicitly modeling that people care about other people (other-regarding preferences). To update standard preferences in our model, we focus on nonstrategic reciprocity motives. Theoretical models (e.g., Rabin, 1993; Levine, 1998; Dufwenberg and Kirchsteiger, 2004; Falk and Fischbacher, 2006), backed up by experimental evidence (e.g., Bellemare and Kröger, 2007; Fehr, Klein, and Schmidt, 2007; Falk, Fehr, and Fischbacher, 2008) show that reciprocity motives strongly influence individual decision-making.

In the present model, we specifically build upon previous work of Cox, Friedman, and Gjerstad (2007) and Cox, Friedman, and Sadiraj (2008). Assume that A's utility function depends on her own material payoff as well as P's payoff. We term the share of P's payoff that A cares about her reciprocity concern. Moreover, A derives utility from P's payoff depending on her reciprocity motive $\rho .{ }^{8}$ Formally, an agent with nonstrategic reciprocity motives solves

$$
\max _{a_{\mathrm{A}}} u\left(\Pi_{\mathrm{A}}\left(a_{\mathrm{A}}\right)\right)+\rho\left[q\left(a_{\mathrm{A}}\right) \Pi_{\mathrm{P}}^{S}+\left(1-q\left(a_{\mathrm{A}}\right)\right) \Pi_{\mathrm{P}}^{F}\right] .
$$

Through the reciprocity motive $\rho$, other-regarding preferences depend on the previous behavior of and the set of alternative actions available to P. Following Cox, Friedman, and Gjerstad (2007), we formalize the reciprocity motive with $\rho\left(a_{\mathrm{P}}\right)=$ $m\left(a_{\mathrm{P}}\right)-m_{0}$, where $m\left(a_{\mathrm{P}}\right)$ is the maximum payoff that A can guarantee herself given P's choice, and $m_{0}$ is A's payoff given some neutral reference decision by P. In the base game, $a_{\mathrm{P}}=$ out appears as a reasonable reference decision by P. Therefore, we specify $\left.\rho\left(a_{\mathrm{P}}\right)\right|_{a_{\mathrm{P}}=\text { in }}=w-\Psi\left(e_{0}\right)>0$ and $\left.\rho\left(a_{\mathrm{P}}\right)\right|_{a_{\mathrm{P}}=\text { out }}=0$ for the base game. If $\mathrm{P}$ chooses to contract with $\mathrm{A}, \mathrm{A}$ will derive utility from increasing $\mathrm{P}$ 's payoff (positive reciprocity). By contrast, reciprocity concerns do not motivate A's choice when $\mathrm{P}$ declines to hire A. Differentiating (2) with respect to $a_{\mathrm{A}}$ yields the firstorder condition

$$
0=-u^{\prime}\left(\Pi_{\mathrm{A}}\left(a_{\mathrm{A}}\right)\right) \Psi^{\prime}\left(a_{\mathrm{A}}\right)+\rho q^{\prime}\left(a_{\mathrm{A}}\right) \Delta \Pi_{\mathrm{P}}
$$

This equation illustrates that A's marginal costs from increasing effort are offset by her marginal utility from reciprocating in kind when $\mathrm{P}$ invests in executing the project. Therefore, A will deviate from the lowest possible effort choice $e_{0}$ when she holds sufficiently high reciprocity motives. If $\mathrm{P}$ anticipates a high enough reciprocity-induced effort choice, she will choose $a_{\mathrm{P}}=i n$ and cooperation will prevail. In contrast to the moral-hazard result under standard preferences, (3) serves as a benchmark for the predictions regarding our treatments.

\footnotetext{
8 The influence of multiple different other-regarding motives can be linked to the agent's utility function using the agent's emotional state $\theta$. In this way Cox, Friedman, and Gjerstad (2007) model the influence of both reciprocity motives and status concerns. As students participate anonymously in our experiment, we rule out status concerns and focus solely on reciprocity motives.
} 


\subsection{Predictions under Exogenous Damages}

We analyze how our predictions change from the benchmark in (3) when either the legal system provides a damage remedy (exogenous), e.g., through statutory law, or the principal stipulates a damage remedy in the contract (endogenous). This section considers the exogenous case.

Except for NTT, exogenous damage remedies expand P's choice set by another stage following A's effort choice (ex post): if the project fails and $\Pi_{\mathrm{P}}^{F}$ occurs, $\mathrm{P}$ can claim damages, $d \in\{0,1\}$. Claiming damages results in a transfer of money from A to $\mathrm{P}$. Let $X$ be the monetary amount of the damage award. Crucially, when such a remedy is available, A's payoff also depends on the success or failure of the project, i.e., the remedy establishes an incentive constraint. Note that this additional stage is similar to the option to steal in some extensions of dictator games (e.g., List, 2007; Bardsley, 2008) or the first stage in the power-to-take game (Bosman and van Winden, 2002). In contrast to the power-to-take game, however, we omit the responders' ability to punish. ${ }^{9}$ We assume thus that the claim will be perfectly enforced, because we seek to understand the effect of different remedies and not of enforcement characteristics of the legal system. Note that in the present game, claiming damages $(d=1)$ is a dominant strategy for a rational principal.

To derive predictions for NTT, we introduce a mere payoff reduction in A's objective function: when the project fails, a payoff reduction of $X$ will automatically be imposed on A. Therefore, A solves

$$
\begin{aligned}
\max _{a_{\mathrm{A}}} q\left(a_{\mathrm{A}}\right) u\left(\Pi_{\mathrm{A}}\left(a_{\mathrm{A}}\right)\right) & +\left[1-q\left(a_{\mathrm{A}}\right)\right] u\left(\Pi_{\mathrm{A}}\left(a_{\mathrm{A}}\right)-X\right) \\
& +\rho\left[q\left(a_{\mathrm{A}}\right) \Pi_{\mathrm{P}}^{S}+\left(1-q\left(a_{\mathrm{A}}\right) \Pi_{\mathrm{P}}^{F}\right] .\right.
\end{aligned}
$$

In contrast with the benchmark case in (2), introducing a payoff reduction does not affect A's reciprocity concern. No transfer takes place from A to P. However, the payoff reduction reduces the maximum payoff that A can guarantee herself given P's choice. Consequently, we define the reciprocity motive as $\left.\rho\left(a_{\mathrm{P}}\right)\right|_{a_{\mathrm{P}}=\text { in }}=$ $w-\Psi\left(e_{0}\right)-X>0$ and $\left.\rho\left(a_{\mathrm{P}}\right)\right|_{a_{\mathrm{P}}=\text { out }}=0$ for NTT. Differentiating (4) with respect to $a_{\mathrm{A}}$ yields

$$
\begin{aligned}
0= & q^{\prime}\left(a_{\mathrm{A}}\right)\left[u\left(\Pi_{\mathrm{A}}\left(a_{\mathrm{A}}\right)\right)-u\left(\Pi_{\mathrm{A}}\left(a_{\mathrm{A}}\right)-X\right)\right] \\
& -\left[q\left(a_{\mathrm{A}}\right) u^{\prime}\left(\Pi_{\mathrm{A}}\left(a_{\mathrm{A}}\right)\right)+\left[1-q\left(a_{\mathrm{A}}\right)\right] u^{\prime}\left(\Pi_{\mathrm{A}}\left(a_{\mathrm{A}}\right)-X\right)\right] \Psi^{\prime}\left(a_{\mathrm{A}}\right) \\
& +\rho q^{\prime}\left(a_{\mathrm{A}}\right) \Delta \Pi_{\mathrm{P}} .
\end{aligned}
$$

In comparison to the benchmark in (3), the first term of (5) is new: it captures A's utility from avoiding the payoff reduction by marginally increasing the project's

\footnotetext{
9 We want to emphasize another crucial difference. The aforementioned games are purely altruistic games in that first-mover decisions are driven by other-regarding motives. In our game, however, the decision to claim damages may be driven not only by preferences over payoff distributions, but also by subjective inferences about other's behavior (the effort choice) from an imperfect signal (the outcome).
} 
probability of success through exerting effort. The second term of (5) captures the expected marginal disutility of increasing effort. This component is higher than the marginal disutility in (3). The third term captures again the marginal utility from reciprocating. Remember that the reciprocity motive $\left.\rho\left(a_{\mathrm{P}}\right)\right|_{a_{\mathrm{P}}=\text { in }}$ is smaller than in the base case, and thus the third term is smaller. Altogether, the effect of introducing a payoff reduction in case of project failure is ambiguous. While the first term of (3) speaks for an increase of effort in comparison to BASE, the second and third terms suggest that effort levels may be lower. Treatment NTT, therefore, serves as an interesting test case: either the mere payoff reduction crowds out reciprocal behavior sufficiently to reduce effort overall, or the monetary disincentive is strong enough to increase A's effort selection in NTT beyond effort levels in BASE. We are confident that the incentives work and predict that A will choose higher effort levels. In turn, $\mathrm{P}$ knows that A will suffer a payoff reduction if the project fails. We predict that $\mathrm{P}$ will anticipate A's selecting higher effort levels to avoid the payoff reduction. Regarding A's effort choice and the frequency of $\mathrm{P}$ investing into the project, we hypothesize:

HyPOTHESIS 1 In NTT, (a) players A on average select higher effort levels than players $A$ in BASE, and $(b)$ the probability that players $P$ choose to invest is larger than in BASE.

We proceed by deriving predictions for fixed ex post damages. The expression (4) does not reflect the specific nature of damage payments as transfer payments. When P's wealth changes after a damage award, the monetary transfer matters for A's reciprocity concerns. The effect of the remedy depends on A's belief $\tau_{d}$ that $\mathrm{P}$ will actually claim damages $(d=1)$. Therefore, A solves

$$
\begin{aligned}
\max _{a_{\mathrm{A}}} q\left(a_{\mathrm{A}}\right) u\left(\Pi_{\mathrm{A}}\left(a_{\mathrm{A}}\right)\right) & +\left[1-q\left(a_{\mathrm{A}}\right)\right] u\left(\Pi_{\mathrm{A}}\left(a_{\mathrm{A}}\right)-\tau_{d} X\right) \\
& +\rho\left[q\left(a_{\mathrm{A}}\right) \Pi_{\mathrm{P}}^{S}+\left(1-q\left(a_{\mathrm{A}}\right)\right)\left(\Pi_{\mathrm{P}}^{F}+\tau_{d} X\right)\right] .
\end{aligned}
$$

Note how the exogenous damages remedy additionally affects the A's reciprocity concern. In comparison to NTT, the reciprocity motive $\rho$ remains unchanged, however, because A can never be certain to avoid paying damages. Similar to NTT, the reciprocity motive $\left.\rho\left(a_{\mathrm{P}}\right)\right|_{a_{\mathrm{P}}=\text { in }}$ is smaller when an exogenous remedy is available than when none is available. Differentiating (6) with respect to $a_{\mathrm{A}}$ yields

$$
\begin{aligned}
0= & q^{\prime}\left(a_{\mathrm{A}}\right)\left[u\left(\Pi_{\mathrm{A}}\left(a_{\mathrm{A}}\right)\right)-u\left(\Pi_{\mathrm{A}}\left(a_{\mathrm{A}}\right)-\tau_{d} X\right)\right] \\
& -\left[q\left(a_{\mathrm{A}}\right) u^{\prime}\left(\Pi_{\mathrm{A}}\left(a_{\mathrm{A}}\right)\right)+\left[1-q\left(a_{\mathrm{A}}\right)\right] u^{\prime}\left(\Pi_{\mathrm{A}}\left(a_{\mathrm{A}}\right)-\tau_{d} X\right)\right] \Psi^{\prime}\left(a_{\mathrm{A}}\right) \\
& +\rho q^{\prime}\left(a_{\mathrm{A}}\right)\left(\Delta \Pi_{\mathrm{P}}-\tau_{d} X\right) .
\end{aligned}
$$

Similar to (5), the first term and second term in (7) capture A's utility from marginally increasing the projects probability of success and her expected marginal disutility of increasing effort, respectively. The main difference lies in the third term, which captures A's marginal utility from reciprocating. While A's reciprocity motive is the same as in (5), her reciprocity concern is smaller. Specifically, the 
share of P's payoff that A cares about is reduced by the damage payment weighted by A's belief that damages will be claimed. The monetary transfer crowds out utility from reciprocating in kind. Conversely, under fixed damages $\mathrm{P}$ can reduce exposure to the failure of the project by claiming damages. Therefore, investing is less risky for her. In fact, claiming damages is a dominant strategy. We hypothesize:

Hypothesis 2 In FDT, (a) players A on average select lower effort levels than players $A$ in NTT, and $(b)$ the probability that players $P$ choose to invest is larger than in NTT.

In a final step, we implement the real-world problem that the damage award may be under- or overcompensatory. We model the ensuing risky damage award with the lottery $\tilde{X}=\left(X^{L}, p ; X^{H}\right)$, where $X^{L}<X, X^{H}>X$, and $X^{L}, X^{H}>0$. To establish comparability to the other cases, we fix $E[\tilde{X}]=X$. Moreover, claiming the remedy remains a dominant strategy for $\mathrm{P}$. Under a risky remedy mechanism, A solves

$$
\begin{array}{rl}
\max _{a_{\mathrm{A}}} & q\left(a_{\mathrm{A}}\right) u\left(\Pi_{\mathrm{A}}\left(a_{\mathrm{A}}\right)\right) \\
& +\left[1-q\left(a_{\mathrm{A}}\right)\right]\left[p u\left(\Pi_{\mathrm{A}}\left(a_{\mathrm{A}}\right)-\tau_{d} X^{L}\right)+(1-p) u\left(\Pi_{\mathrm{A}}\left(a_{\mathrm{A}}\right)-\tau_{d} X^{H}\right)\right] \\
& +\rho\left[q\left(a_{\mathrm{A}}\right) \Pi_{\mathrm{P}}^{S}+\left(1-q\left(a_{\mathrm{A}}\right)\right)\left(\Pi_{\mathrm{P}}^{F}+\tau_{d} E[\tilde{X}]\right)\right] .
\end{array}
$$

Note that the risky nature of the damage award does not affect A's reciprocity motive $\rho$. While A can affect the likelihood of project failure, she cannot influence the occurrence of $X^{L}$ or $X^{H}$ specifically. The maximum payoff she can guarantee herself is $O_{\mathrm{A}}+w-\Psi\left(a_{\mathrm{A}}\right)-E[\tilde{X}]=O_{\mathrm{A}}+w-\Psi\left(a_{\mathrm{A}}\right)-X$ when $a_{\mathrm{P}}=i n$. Therefore, we propose that the reciprocity motive $\rho$ does not depend on whether the damage award is risky. Differentiating (8) with respect to $a_{\mathrm{A}}$ yields

$$
\begin{aligned}
0= & q^{\prime}\left(a_{\mathrm{A}}\right)\left[u\left(\Pi_{\mathrm{A}}\left(a_{\mathrm{A}}\right)\right)-\left[p u\left(\Pi_{\mathrm{A}}\left(a_{\mathrm{A}}\right)-\tau_{d} X^{L}\right)+(1-p) u\left(\Pi_{\mathrm{A}}\left(a_{\mathrm{A}}\right)-\tau_{d} X^{H}\right)\right]\right] \\
& -\left[q\left(a_{\mathrm{A}}\right) u^{\prime}\left(\Pi_{\mathrm{A}}\left(a_{\mathrm{A}}\right)\right)+\left[1-q\left(a_{\mathrm{A}}\right)\right]\left[p u^{\prime}\left(\Pi_{\mathrm{A}}\left(a_{\mathrm{A}}\right)-\tau_{d} X^{L}\right)\right.\right. \\
& \left.\left.+(1-p) u^{\prime}\left(\Pi_{\mathrm{A}}\left(a_{\mathrm{A}}\right)-\tau_{d} X^{H}\right)\right]\right] \Psi^{\prime}\left(a_{\mathrm{A}}\right) \\
& +\rho q^{\prime}\left(a_{\mathrm{A}}\right)\left(\Delta \Pi_{\mathrm{P}}-\tau_{d} E[\tilde{X}]\right) .
\end{aligned}
$$

To derive hypotheses about the influence of risky damage awards, we compare (9) with the fixed-damages case in (7). A's utility from marginally increasing the project's probability of success (first term) is larger than under fixed damages, because $p u(\cdot)+(1-p) u(\cdot)<u(E[\cdot])$ when $u^{\prime}(\cdot)>0, u^{\prime \prime}(\cdot) \leq 0$. Risk-averse agents will take greater strides to avoid paying damages when the damage award can be under- or overcompensatory. A's expected marginal disutilty of increasing effort (second term) is equal to the corresponding term in (7), because $p u^{\prime}(\cdot)+$ $(1-p) u^{\prime}(\cdot)=u^{\prime}(E[\cdot])$ when $u(\cdot)$ is twice differentiable. Finally, the marginal utility from reciprocating (third term) is also unaffected by the damage lottery. While the reciprocity concern is identical in both (9) and (7), i.e., $\Delta \Pi_{\mathrm{P}}-\tau_{d} E[\tilde{X}]=$ $\Delta \Pi_{\mathrm{P}}-\tau_{d} X$, we have argued that the reciprocity motive $\rho$ is independent of the risky nature of the damage award. 
To sum up, utility from marginally increasing the project's probability of success will motivate an agent to exert more effort when damage awards can be under- or overcompensatory. Simultaneously, the expected marginal disutilities from increasing effort and reciprocity-induced marginal utility are unchanged. Independent of the risk nature of the damage award, however, claiming damages is a dominant strategy that reduces P's exposure to project failure. We hypothesize:

Hypothesis 3 In RDT, (a) players A on average select higher effort levels than players $A$ in FDT, and (b) the probability that players $P$ choose to invest is higher than in NTT.

\subsection{Predictions under Endogenous Damages}

This subsection considers the effect of an endogenous damage remedy. When an endogenous stipulation of damages is possible, P's choice set additionally expands ex ante: prior to P's investment choice, she can contractually stipulate a damage payment in case of project failure, $c \in\{0,1\}$. A observes P's decisions whether to stipulate and whether to invest and then selects her effort level. As in the case of exogenous damage remedies, $\mathrm{P}$ can ex post enforce (stipulated) damages contingent on the failure of the project. Note that stipulating damages is a dominant strategy for a rational principal and that the amount of damages is fixed. Very similar to (6), A solves

$$
\begin{gathered}
\max _{a_{\mathrm{A}}} q\left(a_{\mathrm{A}}\right) u\left(\Pi_{\mathrm{A}}\left(a_{\mathrm{A}}\right)\right)+\left[1-q\left(a_{\mathrm{A}}\right)\right] u\left(\Pi_{\mathrm{A}}\left(a_{\mathrm{A}}\right)-c \tau_{d} X\right) \\
+\rho\left[q\left(a_{\mathrm{A}}\right) \Pi_{\mathrm{P}}^{S}+\left(1-q\left(a_{\mathrm{A}}\right)\right)\left(\Pi_{\mathrm{P}}^{F}+c \tau_{d} X\right)\right] .
\end{gathered}
$$

While the difference between (6) and (10) appears almost inconsequential, we argue that a strong difference between the different mechanisms lies in A's reciprocity motive $\rho$. Remember that $\rho$ is a function of A's maximum payoff that she can guarantee herself given P's choice, less her payoff given some neutral reference decision. While all exogenous remedies affected the former, we argue that a stipulated damage mechanism will additionally affect the latter. What is the neutral reference decision under stipulated damages? Prior research consistently finds that choices are menu-dependent. For instance, in different proposer-responder games, responders reject allocations favoring the proposer more often when a fair allocation is possible than when the proposer's choice set was restricted to unfair distributions (e.g., Güth, Huck, and Müller, 2001; Bolton, Brandts, and Ockenfels, 2005; Falk, Fehr, and Fischbacher, 2005). Therefore, we propose that introducing the ex ante choice to stipulate damages shifts P's neutral reference decision as perceived by A to $\left\{a_{\mathrm{P}}=i n, c=0\right\}$ when $\mathrm{P}$ stipulates damages. Moreover, Cox, Friedman, and Sadiraj (2008, p. 40) propose that second movers will "respond more strongly to $[\ldots]$ choices that overturn the status quo than to those that uphold it or that involve no real choice by the first mover." Cox, Servátka, and Vadovič (2016) find supporting evidence for this claim. When P refrains from stipulating damages, we thus propose $a_{\mathrm{P}}=$ out as neutral reference decision. In other words, an omitted 
action is not salient enough to change P's reference decision as perceived by A. Therefore, when stipulation is possible we specify

$$
\rho= \begin{cases}0 & \text { for } a_{\mathrm{P}}=\text { out } \\ w-\Psi\left(e_{0}\right) & \text { for } a_{\mathrm{P}}=i n, c=0 \\ -X & \text { for } a_{\mathrm{P}}=i n, c=1\end{cases}
$$

Note that, given $a_{\mathrm{P}}=i n$, the reciprocity motive $\rho$ is negative when $\mathrm{P}$ chooses to stipulate damages and positive when she does not. This is in stark contrast to fixed exogenous damages. Differentiating (10) with respect to $a_{\mathrm{A}}$ yields

$$
\begin{aligned}
0= & q^{\prime}\left(a_{\mathrm{A}}\right)\left[u\left(\Pi_{\mathrm{A}}\left(a_{\mathrm{A}}\right)\right)-u\left(\Pi_{\mathrm{A}}\left(a_{\mathrm{A}}\right)-c \tau_{d} X\right)\right] \\
& -\left[q\left(a_{\mathrm{A}}\right) u^{\prime}\left(\Pi_{\mathrm{A}}\left(a_{\mathrm{A}}\right)\right)+\left[1-q\left(a_{\mathrm{A}}\right)\right] u^{\prime}\left(\Pi_{\mathrm{A}}\left(a_{\mathrm{A}}\right)-c \tau_{d} X\right)\right] \Psi^{\prime}\left(a_{\mathrm{A}}\right) \\
& +\rho q^{\prime}\left(a_{\mathrm{A}}\right)\left(\Delta \Pi_{\mathrm{P}}-c \tau_{d} X\right) .
\end{aligned}
$$

This expression is almost the same as (7). However, when $\mathrm{P}$ chooses to stipulate a damage payment, A will suffer disutility from reciprocating. As marginally increasing effort imposes psychological costs, we predict that A will reduce her effort level. By contrast, stipulating and enforcing stipulated damages is a dominant strategy that reduces P's exposure to project failure. We hypothesize:

НyPOTHESIS 4 In LDT, (a) when player $P$ chooses to stipulate a transfer payment, players $A$ on average select lower effort levels than players A in FDT, and $(b)$ the probability that players $P$ choose to invest is higher than in NTT.

$$
4 \text { Results }
$$

\subsection{Effort Levels}

We first analyze the effort levels chosen by players A. Figure 2 depicts the relative frequency of effort decisions per treatment. Compared to BASE, effort levels in NTT and FDT appear to be higher, whereas effort levels in LDT appear to be lower. However, discerning from Figure 2 a clear difference across effort levels between BASE and RDT is more difficult.

Table 1 provides quantitative information about differences in effort-level choices across treatments by reporting the mean, standard deviation, and median of such choices. The descriptive statistics support the observations from Figure 2: compared to BASE, mean and median effort-level choices are (1) higher in NTT and FDT, (2) lower in LDT, and (3) about equal in RDT.

To examine whether the differences are statistically meaningful and test our research hypotheses, we conduct one-sided Fisher-Pitman permutation tests. According to Hypothesis 1(a), players A in NTT on average select higher effort levels than players A in BASE. Table 1 supports this result. We reject the null that the distribution of effort-level choices in NTT is smaller than or equal to the distribution of effort-level choices in BASE $(Z=1.9113, p=0.0346)$. 
Figure 2

Effort Choices by Treatment

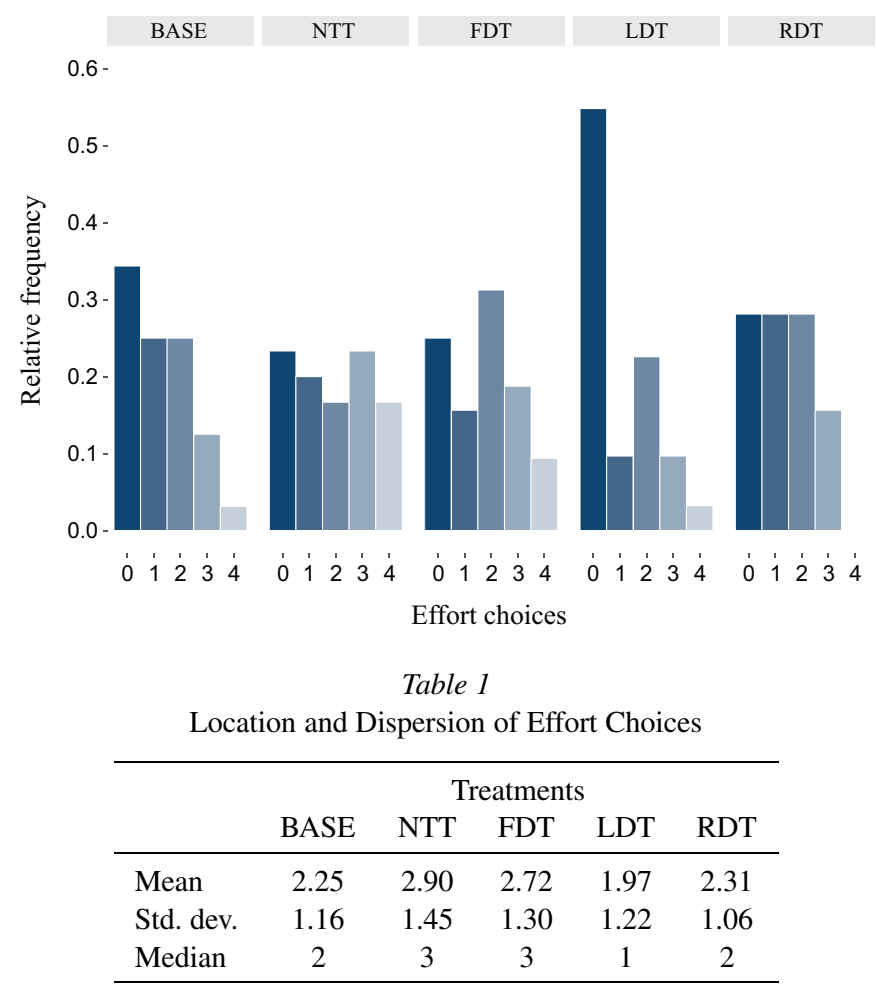

Moreover, in Hypothesis 2(a) we predict that players A in FDT on average select lower effort levels than players A in NTT. The descriptive statistics in Table 1 do not provide a clear indication: while the mean effort choice in FDT is smaller than in NTT, the median effort choice is the same in both treatments. In fact, we cannot reject the null hypothesis that effort-level choices in FDT and NTT are equally distributed $(Z=-0.52245, p=0.3275)$. Insofar as effort-level choices between FDT and NTT are different, this difference is not statistically meaningful.

We proceed with Hypothesis 3(a), which predicts that players A in RDT on average select higher effort levels than players A in FDT. We derived this prediction mainly based on the assumption that agents are risk-averse. Somewhat surprisingly, Table 1 suggests a contrary result, as both mean and median effort-level choices are smaller in RDT than in FDT. Consequently, we also cannot reject the null that the distribution of effort-level choices in RDT is smaller than or equal to that in FDT ( $Z=-1.3597, p=0.9297)$. In fact, we achieve a contrary result in that effort-level choices in RDT are almost significantly smaller than in FDT. 
Finally, we turn to our last prediction regarding effort-level choices. Hypothesis 4(a) holds that players A in LDT on average select lower effort levels (when player P chose to stipulate the transfer payment) than players A in FDT. ${ }^{10}$ The descriptive statistics in Table 1 clearly support the prediction. Indeed, we reject the null that the distribution of effort-level choices in LDT is larger than or equal to that in FDT (one-sided: $Z=-1.427, p=0.0957$ ).

To control for individual-specific characteristics, we estimate treatment effects on effort-level choices with ordered probit models. The different treatments enter the estimation as a dummy variable. We obtain control variables from our posttests and the sociodemographic data on our participants. For each hypothesis, the left panel of Table 2 reports the results of the estimation with the highest quality as measured by the Akaike information criterion (AIC).The results resonate with the results from the Fisher-Pitman permutation tests. In comparison to BASE, NTT has a significantly positive effect on effort-level choices. In comparison to NTT, a fixed transfer payment in FDT has no significant effect on effort-level choices. Similarly, introducing a risky transfer payment in RDT does not lead to significantly higher effort-level choices than does a certain transfer payment in FDT. However, when in LDT players $P$ ex ante stipulate the transfer payment, players A select significantly lower effort levels than for certain ex post transfer payments in FDT. ${ }^{11}$

\subsection{Investment Decisions}

We next turn to the frequency of investment choices of players P. Figure 3 depicts investment choices of players $\mathrm{P}$ per treatment. While the frequency of investment is similar without any remedy in BASE $(53.13 \%)$ and with a payment reduction in NTT $(60.00 \%)$, the frequency of players P investing spikes to nearly $100 \%$ as soon as any form of transfer payment is introduced in FDT (90.63\%), in LDT (93.75\%), and in RDT $(93.55 \%)$.

To analyze the treatment effects on the probability of player P investing, we estimate both a linear probability model and a logit model. We use the same control variables as before. Using NTT as reference treatment allows us to gauge simultaneously whether investment choices in BASE are less frequent than in NTT and whether investment choices in each of FDT, LDT, and RDT are more frequent than in NTT.

The right panel of Table 2 reports results of the linear estimation and average marginal effects of the logit estimation. Compared to treatment NTT, both estimations yield a strong and significant positive effect on the probability that players $\mathrm{P}$ choose to transact with players A for treatments FDT, LDT, and RDT. This result

10 All players A in the LDT treatment chose to stipulate the transfer payment, and therefore we do not need to split the data set.

11 Appendix C (online) contains two robustness checks. The results indicate that (1) the positive effect of NTT compared to BASE is driven by players A more frequently selecting the two highest effort levels and that (2) the negative effect of LDT compared to FDT is driven by players A more often selecting the lowest effort level. 
Table 2

Summary of Regression Analysis

\begin{tabular}{|c|c|c|c|c|c|c|}
\hline \multirow{4}{*}{$\begin{array}{l}\text { Hypotheses } \\
\text { Reference treat- } \\
\text { ment }\end{array}$} & \multicolumn{4}{|c|}{ Effort level } & \multirow{2}{*}{\multicolumn{2}{|c|}{$\begin{array}{c}\text { Investment frequency } \\
\text { (b) to } 4(\mathrm{~b})\end{array}$}} \\
\hline & 1(a) & $2(\mathrm{a})$ & $3(\mathrm{a})$ & $4(\mathrm{a})$ & & \\
\hline & BASE & NTT & \multicolumn{2}{|c|}{ FDT } & \multicolumn{2}{|c|}{ NTT } \\
\hline & \multicolumn{4}{|c|}{ (ordered probit) } & (LPM) & (logit AMEs) \\
\hline BASE & - & - & - & - & $\begin{array}{l}-0.073 \\
(0.095)\end{array}$ & $\begin{array}{l}-0.025 \\
(0.082)\end{array}$ \\
\hline NTT & $\begin{array}{l}0.574^{*} \\
(0.319)\end{array}$ & - & - & - & - & - \\
\hline FDT & - & $\begin{array}{l}-0.006 \\
(0.320)\end{array}$ & - & - & $\begin{array}{c}0.307^{* * *} \\
(0.095)\end{array}$ & $\begin{array}{c}0.222^{* * *} \\
(0.062)\end{array}$ \\
\hline LDT & - & - & - & $\begin{array}{c}-0.355^{*} \\
(0.215)\end{array}$ & $\begin{array}{c}0.336^{* * *} \\
(0.096)\end{array}$ & $\begin{array}{c}0.241^{* * *} \\
(0.056)\end{array}$ \\
\hline RDT & - & - & $\begin{array}{c}-0.390 \\
(0.300)\end{array}$ & - & $\begin{array}{c}0.335^{* * *} \\
(0.095)\end{array}$ & $\begin{array}{c}0.243^{* * *} \\
(0.059)\end{array}$ \\
\hline Age & $\begin{array}{l}0.068^{*} \\
(0.040)\end{array}$ & - & - & - & $\begin{array}{c}-0.011^{*} \\
(0.006)\end{array}$ & $\begin{array}{l}0.010^{*} \\
(0.006)\end{array}$ \\
\hline Male & - & - & - & - & - & - \\
\hline $\begin{array}{l}\text { Risk } \\
\text { aversion }\end{array}$ & $\begin{array}{c}-0.184^{* *} \\
(0.086)\end{array}$ & $\begin{array}{c}-0.028 \\
(0.086)\end{array}$ & $\begin{array}{c}0.028 \\
(0.079)\end{array}$ & $\begin{array}{l}-0.076 \\
(0.082)\end{array}$ & - & - \\
\hline $\begin{array}{l}\text { Ambiguity } \\
\text { aversion }\end{array}$ & $\begin{array}{c}0.028 \\
(0.039)\end{array}$ & $\begin{array}{c}0.047 \\
(0.035)\end{array}$ & $\begin{array}{l}0.037 \\
(0.029)\end{array}$ & - & - & $\begin{array}{c}0.001 \\
(0.001)\end{array}$ \\
\hline SVO type & $\begin{array}{l}-0.540 \\
(0.341)\end{array}$ & - & $\begin{array}{l}-0.549 \\
(0.347)\end{array}$ & - & - & - \\
\hline (Intercept) & - & - & - & - & $\begin{array}{c}0.855^{* * *} \\
(0.166)\end{array}$ & - \\
\hline Res. Dev. & 154.305 & 141.685 & 151.819 & 158.417 & - & 124.738 \\
\hline $\mathrm{AIC}$ & 172.305 & 155.685 & 167.819 & 174.417 & - & 138.738 \\
\hline Res. SE & - & - & - & - & 0.375 & - \\
\hline Adj. $R^{2}$ & - & - & - & - & 0.176 & - \\
\hline
\end{tabular}

Note: ${ }^{*} p<0.10,{ }^{* *} p<0.05,{ }^{* * *} p<0.01$. 
Figure 3

Investment Choices by Treatment

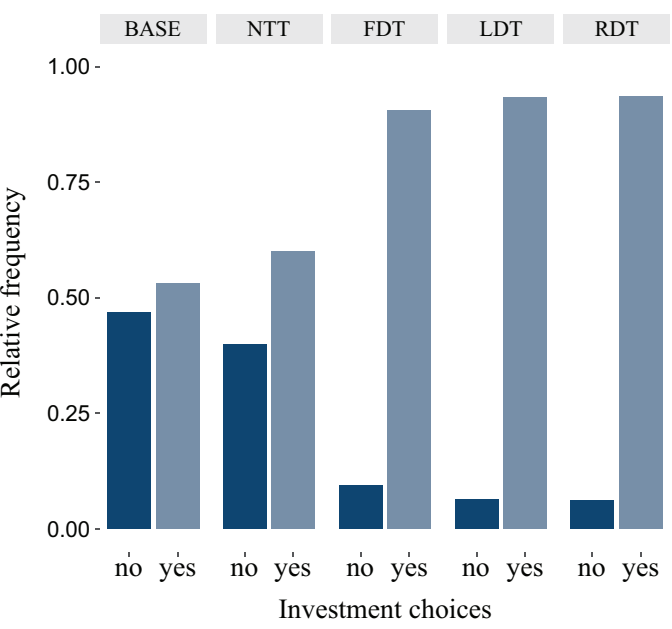

is in line with our Hypotheses 2(b), 3(b), and 4(b). However, contrary to Hypothesis $1(\mathrm{~b})$, the probability that players $\mathrm{P}$ in BASE chose to invest is not significantly lower than in NTT.

\subsection{Point Earnings in the Main Task}

Given (1) the increased frequency of investment in the FDT and LDT conditions as compared to the BASE and NTT conditions and (2) the differences of effort levels across FDT and LDT, we next examine the point earnings of players A and $\mathrm{P}$ obtained during the main task. Specifically, we examine pairs of players that involved a positive investment decision of player P. Players A in FDT earn 622.75 points on average, and players A in LDT earn 632.41 points on average. Based on the results of a two-sided Fisher-Pitman permutation test, we cannot reject the null hypothesis that the distribution of point earnings of players A is equal in FDT and LDT ( $Z=-0.1891, p=0.8616$ ). Therefore, players A earn the same number of points across these treatments.

Players P in FDT earn 751.72 points on average. However, players P in LDT only earn 641.38 points on average. In fact, a two-sided Fisher-Pitman permutation test leads us to reject the hypotheses that point earnings of players $\mathrm{P}$ are equally distributed between FDT and LDT $(Z=2.0741, p=0.0647)$. We conclude that players $\mathrm{P}$ in LDT earn significantly less points than players $\mathrm{P}$ in FDT. 


\section{Discussion}

The early economic literature identified various benefits of contracting for damage measures. Liquidated-damages clauses have been recognized as insuring buyers against nonperformance (Goetz and Scott, 1977), enabling screening buyers with unobservable valuations (Schwartz, 1990; Stole, 1992), preventing overinvestments (Cooter, 1985), and preventing entry by competitors (Chung, 1992; Aghion and Bolton, 1987). ${ }^{12}$ A second strand of literature highlighted the potential role of stipulating sanctions as a means for inducing efficient cooperative investments (Edlin, 1996; Edlin and Reichelstein, 1996; Hart and Moore, 1999; Maskin and Tirole, 1999).

Recent contributions focus on the effect of party-stipulated remedies on the interpersonal dynamics and normative understandings about contract breach (Wilkinson-Ryan and Baron, 2009). Experimental findings suggest, for instance, that the presence of liquidated-damages clauses may crowd out contracting parties' moral resistance to contract breach (Wilkinson-Ryan, 2010).

In line with this more recent research, the theory, model, and experiment in this article build on the common observation that people also have other-regarding, nonmonetary preferences. To that end, our model assumes that contracting parties' utility function reflects reciprocal concerns.

As we predicted, the findings suggest that when sanctions for uncooperative behavior are formalized by one of the parties, this degrades the interpersonal dynamic between the contracting parties. The results indicate that stipulating sanctions for breach not only erodes the interpersonal trust and positive reciprocity, but actually goes so far as tipping the reciprocity motive, inducing negative reactions by the other party, whose behavior becomes subject to moral hazard. One possible interpretation is that when a contracting party specifies or formalizes sanctions for uncooperative behavior ahead of time, this makes the expectation of breach more salient, signaling a lack of trust in the agent. In this regard, inserting a liquidateddamages clause reduces the agent's effort in completing the contract.

Our findings suggest that the adverse reaction by agents to liquidated damages is triggered by the stipulation of the damage remedy by the principal, not by principals' pending decision to claim damages. First, the principal's decision to initiate a transfer payment for nonperformance takes place after the agent has selected his or her effort level. Second, although our FDT treatment incorporates an identical ex post claiming stage, we do not observe any adverse reaction by agents there.

An interesting finding that runs through our results is that principals fail to anticipate the eroding effect of stipulating damages on cooperative behavior. To the contrary, implementing a damage payment appears to evoke a sense of security among principals indistinguishable from the exogenously provided damage remedies. This confidence seems unwarranted given the reduced effort levels. It suggests

12 Spier and Whinston (1995) demonstrate that the efficiency advantages of penalty clauses can disappear on taking into account renegotiation and potential overinvestments. 
a lack of anticipation and empathy on behalf of participants. Our data indicates that this failure is a source of inefficiency. Agents in LDT earn as many points in the main task as their colleagues in FDT, but by relying on the false security of a liquidated-damages clause, principals in LDT earn significantly less points than in FDT. Overall, the results from our study suggest that when stipulating damages, contracting parties attain less cooperative surplus than when they are subject to an exogenously imposed remedy.

Although our experimental design incorporates several real-world contracting features, we stylized a number of aspects in order to implement the setting in the laboratory. First, while the BASE treatment (no compensation) is the background to all treatments, in most legal settings expectation damages or specific performance is the default if parties do not include a damage stipulation in the contract.

This difference affects the results in at least two possible ways. On the one hand, the material effect of a liquidated-damages clause is of course more substantial than in a real-world setting, where the difference between privately stipulated damages and expectation damages is expected to be more minor, especially given the legal restrictions on punitive sanctions in contract law observed in most legal systems. On the other hand, in our experimental setting the principal's decision to include a liquidated-damages clause is quite reasonable in light of the lack of any protection against breach in the alternative. By contrast, insisting on a liquidated-damages clause might be perceived as a stronger signal of distrust if the default legal background already protects the expectation interest of the principal. In this regard, our findings might in fact be stronger in real-world settings where liquidated-damages clauses depart from a default that is more protective than in our experimental setting.

Second, in our experimental setting the principal unilaterally sets the liquidateddamages award. In many real-world situations, of course, liquidated-damages clauses result from bilateral negotiations between contracting parties. Negative reciprocity likely will be less pronounced when liquidated-damages awards are the result of fair, even-handed negotiations. Note however that the liquidated-damages clause in our treatment merely reflect the expectation damage award - fully in line with the more restrictive legal doctrine that restricts liquidated-damages stipulations to amounts that reflect expectation damages in situation when proving harm might be burdensome. In any event, our results emphasize the importance for promisees to engage in a fair bargaining over damage clauses in order to avoid the adverse effects documented in this article.

\section{Conclusion}

Recent evidence suggests that liquidated-damages clauses provide efficiency advantages by crowding out contracting parties' deontological concerns about efficient breach. In this paper we highlight an important downside to ex ante damage stipulations by parties. Based on findings obtained in a controlled laboratory exper- 
iment, we suggest that express damage stipulations trigger negative reciprocity and moral hazard, reducing performance by contract promisors. Such negative effects are absent when damages are exogenously imposed.

\section{References}

Aghion, P., and P. Bolton (1987), "Contracts as Barrier to Entry," The American Economic Review, 77(3), 388-401.

Bardsley, N. (2008), "Dictator Game Giving: Altruism or Artefact?" Experimental Economics, 11(2), 122-133.

Bellemare, C., and S. Kröger (2007), "On Representative Social Capital," European Economic Review, 51(1), 183-202.

Bolton, G. E., J. Brandts, and A. Ockenfels (2005), "Fair Procedures: Evidence from Games Involving Lotteries," The Economic Journal, 115(506), 1054-1076.

Bosman, R., and F. van Winden (2002), "Emotional Hazard in a Power-to-Take Experiment," The Economic Journal, 112(476), 147-169.

Charness, G., and M. Dufwenberg (2006), "Promises and Partnership," Econometrica, 74(6), $1579-1601$.

Chung, T.-Y. (1992), "On the Social Optimality of Liquidated Damage Clauses: An Economic Analysis," The Journal of Law, Economics, \& Organization, 8(2), 280-305.

Cooter, R. D. (1985), "Unity in Tort, Contract, and Property: The Model of Precaution," California Law Review, 73(1), 1-51.

Cox, J. C., D. Friedman, and S. Gjerstad (2007), "A Tractable Model of Reciprocity and Fairness," Games and Economic Behavior, 59(1), 17-45.

—, - , and V. Sadiraj (2008), "Revealed Altruism," Econometrica, 76(1), 31-69.

—, M. Servátka, and R. Vadovič (2016), "Status Quo Effects in Fairness Games: Reciprocal Responses to Acts of Commission versus Acts of Omission," Experimental Economics, published Online First March 7, DOI: 10.1007/s10683-016-9477-0.

Crosetto, P., O. Weisel, and F. Winter (2012), "A Flexible z-Tree Implementation of the Social Value Orientation Slider Measure (Murphy et al. 2011): Manual," Jena Economic Research Paper 2012-062, Friedrich-Schiller University Jena and Max Planck Institute of Economics, Jena.

Dufwenberg, M., and G. Kirchsteiger (2004), “A Theory of Sequential Reciprocity,” Games and Economic Behavior, 47(2), 268-298.

Edlin, A. S. (1996), "Cadillac Contracts and Up-Front Payments: Efficient Investment under Expectation Damages," The Journal of Law, Economics, \& Organization, 12(1), 98-118.

— and S. Reichelstein (1996), "Holdups, Standard Breach Remedies, and Optimal Investment," The American Economic Review, 86(3), 478-501.

Eisenberg, M. A. (1995), "The Limits of Cognition and the Limits of Contract," Stanford Law Review, 47(2), 211-259.

Falk, A., E. Fehr, and U. Fischbacher (2005), "Driving Forces behind Informal Sanctions," Econometrica, 73(6), 2017-2030.

- , - , and - (2008), "Testing Theories of Fairness-Intentions Matter," Games and Economic Behavior, 62(1), 287-303.

— and U. Fischbacher (2006), "A Theory of Reciprocity," Games and Economic Behavior, 54(2), 293-315.

Fehr, E., A. Klein, and K. M. Schmidt (2007), "Fairness and Contract Design," Econometrica, 75(1), 121-154.

Fischbacher, U. (2007), "z-Tree: Zurich Toolbox for Ready-Made Economic Experiments," Experimental Economics, 10(2), 171-178. 
Gneezy, U., A. Imas, and J. List (2015), "Estimating Individual Ambiguity Aversion: A Simple Approach," Working Paper 5220, CESifo, Munich.

Goetz, C. J., and R. E. Scott (1977), "Liquidated Damages, Penalties and the Just Compensation Principle: Some Notes on an Enforcement Model and a Theory of Efficient Breach," Columbia Law Review, 77(4), 554-594.

Greiner, B. (2015), "Subject Pool Recruitment Procedures: Organizing Experiments with ORSEE," Journal of the Economic Science Association, 1(1), 114-125.

Güth, W., S. Huck, and W. Müller (2001), "The Relevance of Equal Splits in Ultimatum Games," Games and Economic Behavior, 37(1), 161-169.

Hart, O., and J. Moore (1999), "Foundations of Incomplete Contracts," The Review of Economic Studies, 66(1), 115-138.

Holt, C. A., and S. K. Laury (2002), "Risk Aversion and Incentive Effects," The American Economic Review, 92(5), 1644-1655.

Kronman, A. T., and R. A. Posner (1979), The Economics of Contract Law, Little Brown \& Co., London.

Levine, D. K. (1998), "Modeling Altruism and Spitefulness in Experiments," Review of Economic Dynamics, 1(3), 593-622.

List, J. A. (2007), "On the Interpretation of Giving in Dictator Games," Journal of Political Economy, 115(3), 482-493.

Maskin, E., and J. Tirole (1999), "Unforeseen Contingencies and Incomplete Contracts," The Review of Economic Studies, 66(1), 83-114.

Mitzkewitz, M., and R. Nagel (1993), "Experimental Results on Ultimatum Games with Incomplete Information,” International Journal of Game Theory, 22(2), 171-198.

Rabin, M. (1993), "Incorporating Fairness into Game Theory and Economics," The American Economic Review, 83(5), 1281-1302.

Rea, S. A., Jr. (1984), "Efficiency Implications of Penalties and Liquidated Damages," The Journal of Legal Studies, 13(1), 147-167.

Schwartz, A. (1990), "The Myth that Promisees Prefer Supracompensatory Remedies: An Analysis of Contracting for Damage Measures," The Yale Law Journal, 100(2), 369-407.

Selten, R. (1967), "Die Strategiemethode zur Erforschung des eingeschränkt rationalen Verhaltens im Rahmen eines Oligopolexperimentes," in: H. Sauermann (ed.), Beiträge zur experimentellen Wirtschaftsforschung, J.C.B. Mohr (Paul Siebeck), Tübingen, pp. 136-168.

Sloof, R., E. Leuven, H. Oosterbeek, and J. Sonnemans (2003), "An Experimental Comparison of Reliance Levels under Alternative Breach Remedies," The RAND Journal of Economics, 34(2), 205-222.

Spier, K. E., and M. D. Whinston (1995), “On the Efficiency of Privately Stipulated Damages for Breach of Contract: Entry Barriers, Reliance, and Renegotiation," The RAND Journal of Economics, 26(2), 180-202.

Stole, L. A. (1992), "The Economics of Liquidated Damage Clauses in Contractual Environments with Private Information," The Journal of Law, Economics, \& Organization, 8(3), 582-606.

Talley, E. L. (1994), “Contract Renegotiation, Mechanism Design, and the Liquidated Damages Rule," Stanford Law Review, 46(5), 1195-1243.

Wilkinson-Ryan, T. (2010), "Do Liquidated Damages Encourage Breach? A Psychological Experiment," Michigan Law Review, 108(5), 633-671.

- and J. Baron (2009), "Moral Judgment and Moral Heuristics in Breach of Contract," Journal of Empirical Legal Studies (jels), 6(2), 405-423. 
Sven Hoeppner

Ghent University

Universiteitstraat 4

9000 Ghent

Belgium

sven.hoppner@ugent.be

Ben Depoorter

University of California Hastings

200 McAllister Street

San Francisco, CA 94102

U.S.A.

depoorter@uchasting.edu
Lars Freund

Max Planck Institute

for Research on Collective Goods

Kurt-Schumacher-Str. 10

53113 Bonn

Germany

freund@coll.mpg.de 